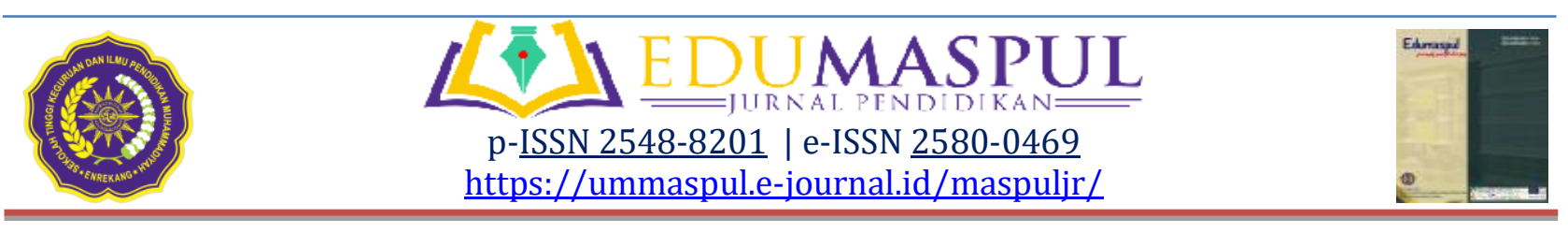

\title{
Pelestarian Cerita Rakyat Kabupaten Pandeglang dan Pemanfaatannya sebagai Bahan Pembelajaran Apresiasi Sastra
}

\author{
Sopyan Sauri'; Purlilaiceu ${ }^{2}$
}

\author{
1,2Program Studi Diksatrasiada Universitas Mathla'ul Anwar Banten, Indonesia \\ $\bowtie$ Corresponding email: ${ }^{1}$ sopyannsaurii@gmail.com; 2purlilaiceu83@gmail.com
}

\begin{abstract}
Receive: 21-09-2019
Accepted: 28-09-2019

Published: 05-10-2019

Abstrak: Penelitian ini bertujuan untuk menginventarisasi cerita rakyat di kabupaten pandeglang sebagai upaya pelestarian yang pada akhirnya menjadi kumpulan cerita rakyat berbentuk buku cerita serta pemanfaatannya sebagai bahan pembelajaran apresiasi sastra. Penelitian ini terdiri atas tiga tahap yaitu tahap prapenelitian, tahap penelitian, dan tahap pengelolaan data.Tahap prapenelitian digunakan untuk membuat rancangan mengenai berapa dan cerita apa yang akan diteliti. Tahap penelitian menggunakan dua cara, pertama langsung melakukan observasi ke seulurh wilayah Kabupaten Pandeglang dan cara kedua adalah dengan menggunakan teknik studi pustaka. Teknik pustaka dilakukan untuk mencari informasi dan sumber pustaka resmi, seperti Perpustakaan Daerah dan perpustakaan perguruan tinggi di Banten. Teori yang digunakan dalam penelitian ini adalah teori dunia foklor dan cerita rakyat. Penelitian ini menggunakan pendekatan model inventarisasi sedangkan metode yang digunakan adalah metode deskriptif analitik. Hasil penelitian pelestarian cerita rakyat di Kabupaten Pandeglang adalah kumpulan cerita rakyat di Kabupaten Pandeglang yang berisi empatbelas cerita rakyat yaitu Cerita Rakyat Pangeran Pandeglang dan Putri Cadarasi, Legenda Tanjung Lesung, Cerita Rakyat Batu Tulis Citaman, Cerita Rakyat Syekh Maulana Mansyurudin Cikadueun. Cerita Rakyat Prasasti Batu Tulis Munjul, Cerita Rakyat Sungai Cisajir, Cerita rakyat Asal Mula Desa Mekarjaya Kec Cikedal, Cerita Rakyat Regen Boncel Caringin, Cerita Rakyat Situ Cikedal, Cerita Rakyat Ki Mintul dan Nyi Mintul, Cerita Rakyat Ki Ipuh Raja Buhaya Ti Ciliman, Cerita Rakyat Nyi Jompong, Cerita Rakyat Leuwi Lamot dan Belut Raksasa dan Cerita Rakyat Sumur Cidewata. Kumpulan cerita rakyat tersebut digunakan sebagai bahan pembelajaran apresiasi sastra untuk semua jenjang pendidikan seperti SMP, SMA bahkan Perguruan Tinggi serta bahan bacaan untuk para akademisi dan masyarakat umum lainnya di Kabupaten Pandeglang pada khususnya dan Banten serta Indonesia pada umumnya.
\end{abstract}

Kata kunci: Pelestarian cerita rakyat, bahan pembelajaran

\begin{abstract}
Preservation of the People's Story of Pandeglang Regency and Its Utilization as a Learning Material for Literature Appreciation. This study aims to inventory folklore in Pandeglang district as a preservation effort which eventually becomes a collection of folklore in the form of story books and their use as learning materials for literary appreciation. This research consists of three stages, namely the pre-research stage, the research stage, and the data management stage. The pre-research stage is used to make a design of how much and what stories will be examined. The research phase uses two ways, first is to directly observe the whole area of Pandeglang Regency and the second is to use literature study techniques. Library technique is carried out to find information and sources of official libraries, such as the Regional Library and university libraries in Banten. The theory used in this research is fochlor world theory and folklore. This research uses an inventory model approach while the method used is descriptive analytic method. The results of research on the preservation of folklore in Pandeglang Regency are a collection of folklore in Pandeglang Regency which contains fourteen folklore stories, namely the Folk Story of Prince Pandeglang and Putri Cadarasi, The Legend of Tanjung Lesung, the Citaman Slate Folk Story, Folk Story of Sheikh Maulana Mansyurudin Cikadueun. Munjul
\end{abstract}


Slate Inscription Folklore, Cisajir River Folklore, Folklore Origin of Mekarjaya Village, Cikedal District, Regen Boncel Caringin Folklore, Situ Cikedal Folklore, Folklore Ki Mintul and Nyi Mintul, Folklore Ki Ipuh Raja Buhaya Ti Ciliman, Stories Nyi Jompong Folk, Leuwi Lamot Folk Story and Giant Eel and Folk Story of Cidewata Well. The collection of folklore is used as learning material for literature appreciation for all levels of education such as junior high, high school and even universities as well as reading material for academics and other general public in Pandeglang Regency in particular and Banten and Indonesia in general.

Keywords: Preservation of folklore, learning materials

\section{PENDAHULUAN}

Di Indonesia terdapat banyak jenis kesusastraan, salah satunya yang kita ketahui adanya cerita rakyat. Cerita rakyat adalah cerita yang berkembang pada masyarakat tertentu yang perkembangannya bersifat lisan dari mulut kemulut dan dianggap sebagai milik bersama. Pada zaman dahulu carita rakyat biasanya digunakan oleh para orang tua untuk menghibur anaknya yang hendak tidur.

Dananjaya (2007) menyatakan bahwa folk adalah sinonim dari kolektif, yang juga memiliki ciri-ciri pengenal fisik atau kebudayaan yang sama, serta mempunyai kesadaran kepribadian sebagai kesatuan masyarakat. Lore adalah tradisi folk yaitu sebagian dari kebudayaan yang diwariskan secara turun menurun secara lisan atau melalui contoh yang disertai gerakan isyarat atau alat pembantu pengingat (mnemonic device). Kebudayaan yang sama maksudnya sebuah adat istiadat yang sama pada sebuah kelompok masyarakat tertentu. Kesadaran kepribadian adalah sebuah kesamaan visi misi atau pandangan hidup yang diemban dalam sebuah kelompok tertentu. Dan diwariskan dari generasi ke generasi sehingga langgeng dan menjadi ciri khas suatu perkumpulan masyarakat tertentu.

Salah satu bagian dari folklore adalah cerita rakyat. Cerita rakyat merupakan cerita yang berasal dari suatu kelompok masyarakat tertentu dan berkembang dalam masyarakat tersebut secara turun menurun dari generasi ke enerasi berikutnya dan disampaikan secara lisan. Cerita rakyat menjadi ciri khas suatu daerah yang mempunyai kultur budaya yang beraneka ragam mencakup kekayaan budaya dan sejarah yang dimiliki masing-masing daerah. Cerita rakyat adalah suatu kebudayaan yang tumbuh dan berkembang di masyarakat yang diwariskan secara lisan sebagai milik bersama.

Sudjiman (2006) menyatakan bahwa cerita rakyat adalah kisahan atau anonym yang tidak terikat oleh ruang dan waktu yang beredar secara lisan di tengah masyarakat. Kisahan tersebut dapat berupa cerita yang benar-benar terjadi atau berupa khayalan yang berfungsi sebagai media hiburan pada masyarakat tertentu. Cerita tersebut bertahan sepanjang masa dan sulit untuk ditinggalkan oleh masyarakatnya. Dalam Kamus Besar Bahasa Indonesia (2013) dijelaskan, bahwa cerita rakyat adalah cerita dari zaman dahulu yang hidup di kalangan rakyat dan diwariskan secara lisan. Cerita rakyat dengan demikian bisa dipandang sebagai salah satu bentuk tradisi lisan yang memakai media bahasa.

Berdasarkan uraian tersebut dapat disimpulkan bahwa cerita rakyat adalah suatu cerita yang hidup dan berkembang di kalangan masyarakat yang penyebarannya terjadi secara lisan yang turun-temurun dari generasi kegenerasi 
berikutnya. Cerita tersebut tidak terikat ruang dan waktu dan merupakan sebuah ekspersi kebudayaan dan merupakan cerimnan masa lalu yang mengungkap apa yang terjadi dimasanya.

Di kalangan masyarakat Kabupaten Pandeglang, memiliki keanekaragaman sastra daerah yang kini hampir punah. Cerita rakyat atau sastra daerah yang ada di kabupaten pandeglang diantaranya adalah, Cerita Rakyat Pangeran Pandeglang dan Putri Cadarasi,, Legenda Tanjung Lesung, Cerita Rakyat Batu Tulis Citaman, Cerita Rakyat Syekh Maulana Mansyurudin Cikadueun. Cerita Rakyat Prasasti Batu Tulis Munjul, Cerita Rakyat Sungai Cisajir, Cerita rakyat Asal Mula Desa Mekarjaya Kec Cikedal, Cerita Rakyat Regen Boncel Caringin, Cerita Rakyat Situ Cikedal, Cerita Rakyat Ki Mintul dan Nyi Mintul, Cerita Rakyat Ki Ipuh Raja Buhaya Ti Ciliman, Cerita Rakyat Nyi Jompong, Cerita Rakyat Leuwi Lamot dan Belut Raksasa dan Cerita Rakyat Sumur Cidewatadan masih banyak yang lainnya.

Untuk mengantisipasi kepunahan cerita rakyat tersebut, maka perlu adanya upaya inventarisasi cerita rakyat sebagai upaya pelestarian. Kalau dibiarkan mengalir apa adanya dan tidak ada usaha penggalian sastra daerah ini, maka seiring berjalannya waktu dan perkembangan arus globalisasi sastra derah terutama cerita rakyat terancam terlupakan. Padahal cerita rakyat atau folklore masih banyak mengandung nilai-nilai yang sangat tinggi sarta mempunyai muatan isi yang perlu diwarisi oleh pemakainya.

Filosofi pelestarian didasarkan pada kecenderungan manusia untuk melestarikan nilai-nilai budaya pada masa yang telah lewat namun memiliki arti penting bagi generasi selanjutnya. Nilainilai tersebut dianggap bermakna dan bermanfaat untuk kehidupan mereka dan rerlu untuk dijaga dan dipertahankan keberadaannya. Pelestarian dalam Kamus Besar Bahasa Indonesia (2013) berasal dari kata dasar lestari, yang artinya adalah tetap selama-lamanya tidak berubah. Kemudian dalam kaidah penggunaan bahasa Indonesia, penggunaan awalan pe dan akhiran-an artinya digunakan untuk menggambarkan sebuah proses atau upaya (kata kerja). Jadi berdasarkan kata kunci lestari ditambah awalan pe-dan akhiran-an, maka yang dimaksud pelestarian adalah upaya untuk membuat sesuatu tetap selama-lamanya tidak berubah dan dapat didefinisikan sebagai upaya untuk mempertahankan sesuatu agar tetap sebagaimana adanya.

Pontoh (2009), mengemukakan bahwa konsep awal pelestarian adalah konservasi, yaitu upaya melestarikan dan melindungi sekaligus memanfaatkan sumber daya suatu tempat dengan adaptasi terhadap fungsi baru, tanpa menghilangkan makna kehidupan budaya. Pelestarian itu dilakukan untuk melindungi agar hal tersebut tetap terjaga keberadaannya, tetap dan tidak berubah. Tetap dan tidak berubah bukan berarti dibiarkan begitu saja tetapi dimanfaatkan untuk kepentingan bersama. Menyesuaikan fungsinya dengan keadaan jaman saat ini. Dengan tidak mengubah makna dan nilai yang terkandung di dalamnya.

Hasil inventarisasi cerita rakyat tersebut dapat dimanfaatkan sebagah bahan pembelajaran. Bahan ajar adalah seperangkat sarana atau alat pembelajaran yang berisikan materi pembelajaran, metode, batasan-batasan, dan cara mengevaluasi yang didesain secara sistematis dan menarik dalam rangka mencapai tujuan yang diharapkan, yaitu mencapai kompetensi atau subkompetensi dengan segala kompleksitasnya (Widodo dan Jasmadi 
dalam Lestari, 2013). Pengertian ini menjelaskan bahwa suatu bahan ajar haruslah dirancang dan ditulis dengan kaidah intruksional karena akan digunakan oleh guru untuk membantu dan menunjang proses pembelajaran. Lain halnya dengan Ruhimat (2011) menyatakan bahan atau materi pembelajaran pada dasarnya adalah "isi" dari kurikulum, yakni berupa mata pelajaran atau bidang studi dengan topik/subtopik dan rinciannya.

Cerita rakyat hasil inventarisasi selanjutnya di manfaatkan sebagai bahan pembelajaran apresiasi sastra. Effendi (2006) mengungkapkan bahwa apresiasi sastra adalah kegiatan menggauli karya sastra secara sungguh-sungguh sehingga menumbuhkan pengertian, penghargaan, kepekaan, pikiran kritis, dan kepekaan perasaan yang baik terhadap karya sastra. Apresiasi berarti menghargai atau menikmati sebuah karya sastra baik secara langsung maupun tidak langsung, dengan tujuan untuk menyenangkan batin. Sesorang akan mendapatkan kesenangan manakala ia dapat memakanai nilai-nilai keiindahan yang terdapat dalam karya sastra tersebut. Hal ini senada dengan pendapat Sugono (2008) yang mengungkapkan bahwa apresiasi diartikan sebagai usaha pengenalan suatu nilai terhadap nilai yang lebih tinggi. Pendapat lain disampaikan oleh Yunarti (2011), apresiasi sastra adalah suatu cara agar kita dapat menikmati suatu karya sastra sehingga timbul penghargaan dari diri kita terhadap karya sastra tersebut.

Lebih lanjut Irman (2008) menyatakan bahwa ada dua jenis yaitu apresiasi yang bersifat kinetik atau sikap tindakan dan apresiasi yang bersifat verbalitas. Apresiasi bersifat kinetik, yaitu sikap memberikan minat pada sebuah karya sastra lalu berlanjut pada keseriusan untuk melakukan langkahlangkah apresiatif secara aktif. Misalnya, untuk bentuk karya sastra berupa prosa fiksi seperti cerpen dan novel, tindakan apresiatifnya ialah memilih cerpen atau novel yang sesuai kehendaknya. Selanjutnya, membaca dan menyenangi novel sejenis, menyenangi tema atau pengarangnya, memahami pesanpesannya, jalan ceritanya, serta mengenal tokoh-tokoh dan watak tokohnya, bahkan secara ekstrim ada yang berkeinginan mengindentifikasi diri menjadi tokoh yang digemari dalam karya prosa tersebut. Puncak dari sikap apresiasinya ialah ingin dapat membuat karya cerpen atau novel seperti itu. Setidak-tidaknya dapat memberikan komentar atau tanggapan tentang hal yang berhubungan dengan novel yang digemari.

\section{METODE}

Pendekatan yang digunakan dalam penelitian ini adalah pendekatan model inventarisasi. Pendekatan model inventarisasi adalah suatu proses atau langkah langkah untuk menginventarisasi cerita-cerita rakyat yang ada di Kabupaten Pandeglang yang belum pernah diinventarisasi. Metode yang digunakan dalam penelitian ini adalah metode kualitatif deskriptif. Metode kualitatif deskriptif adalah metode yang bertujuan untuk mendeskripsikan cerita rakyat dan menganalisisnya dalam bentuk model inventarisasi. Penelitian ini bertujuan untuk mengumpulkan ceritacerita rakyat di Kabupaten Pandeglang kemudian disusun menjadi buku bacaan yang dapat dimanfaatkan sebagai bahan pembelajaran di SMA/K dan Perguruan Tinggi.

Teknik pengumpulan data dalam Penelitian pelestarian cerita rakyat di 
Kabupaten Pandeglang ini terdiri atas tiga tahap yaitu tahap prapenelitian, tahap penelitian, dan tahap pengelolaan data. Tahap prapenelitian digunakan untuk membuat rancangan mengenai berapa dan cerita apa yang akan diteliti. Sebelum membuat sebuah rancangan, harus melakukan observasi. Observasi dilakukan dengan dua cara pertama observasi ke seulurh wilayah Kabupaten Pandeglang yang terdapat cerita rakyat. Kedua, observasi dengan menggunakan teknik studi pustaka. Teknik pustaka dilakukan untuk mencari informasi dan sumber pustaka resmi. Teknik tersebut dilakukan melalui Dinas pendidikan Kab Pandeglang, Perpustakaan Daerah, Perpustakaan Perguruan tinggi di Banten seperti perpustakaan Unma Banten, Untirta Serang, STKIP Setia Budhi Rangkasbitung dan perpustakaan perguruan tinggi lainnya di wilayah Provinsi Banten. Melalui Perpustakaan Perguruan tinggi di wilayah Banten diperoleh informasi awal mengenai data cerita rakyat apa saja yang terdapat di Kabupaten Pandeglang baik yang sudah maupun belum tertulis untuk kemudian dilakukan penelitian langsung pada lokasi di mana cerita rakyat itu lahir dan berkembang.

Tahap selanjutnya yaitu penelitian langsung di lapangan. Tahap ini dilakukan dengan tujuan untuk mendapatkan data mengenai cerita rakyat yang akan diteliti. Peneliti melakukan pencarian data cerita rakyat melalui wawancara kepada masyarakat pemilik cerita rakyat tersebut.

Tahap pengolahan data adalah tahap penulisan cerita rakyat hasil wawancara dengan masyarakat pemikik cerita rakyat tersebut. Juga penyalinan kembali cerita takyat dari hasil studi pustaka dari Perpustakaan Perguruan Tinggi di wilayah Banten.

\section{PEMBAHASAN}

\section{a. Cerita Rakyat Kabupaten Pandeglang}

Kabupaten pandeglang adalah kabupaten yang berada di ujung barat pulau jawa yang masuk ke wilayah provinsi banten. Kabupaten pandeglang berbatasan dengan kabupaten serang di wilayah utara, kabupaten lebak di bagian timur. Di bagian barat berbatasan dengan selat sunda dan bagian selatan berbatasan dengan samudera hindia. Wilayah kabupaten pandeglang termasuk pulau yang berada disekitarnya diantaranya Pulau Panaitan (di sebelah barat, dipisahkan dengan Selat Panaitan), serta sejumlah pulau-pulau kecil di Samudra Hindia, termasuk Pulau Deli dan Pulau Tinjil. Semenanjung Ujung Kulon merupakan ujung paling barat Pulau Jawa, di mana terdapat suaka margasatwa tempat perlindungan hewan badak bercula satu yang kini hampir punah.

Berdasarkan catatan sejarah wilayah kabupaten pandeglang pernah menjadi daerah kekuasaan kerajaan salakanagara dengan rajanya Dewawarman 1 sampai 8. Setelah berakhirnya kerajaan salakanagara daerah pandeglang di bawah kekuasaan kerajaan tarumanegara dengan rajanya yang terkenal dengan nama Purnawarman. Berakhirnya kerajaan tarumanegara daerah pandeglang berada di bawah kekuasaan kerajaan sunda. Tak lama dari itu wilayah pandeglang menjadi daerah kekuasaan kerajaan Padjajaran dengan rajanya yang terkenal adalah Prabu Siliwangi. Berakhirnya kerajaan Padjajaran wilayah Pandeglang berada di bawah kekuasaan Kesultanan Banten. Musnahnya kerajaan banten berganti penjajahan belanda dan 
jepang yang akhirnya merdeka tahun 1945 menjadi bagian dari Negara Indonesia. dari perjalanan sejarah peradaban manusia di tanah pandeglang maka terdapat kisah-kisah manusia jaman dahulu yang berinteraksi dengan sesamanya. Lakon yang dilakukan oleh jawara, kyai, pendekar-pendekar sakti menjalankan misinya untuk menggapai kedigjayaan yang abadi. Semua kisah tersebut diantaranya ada yang terkategorikan sebagai cerita rakyat.

Berdasarkan hasil penelitian yang dilakukan dengan menggunakan metode kajian pustka dan observasi langsung ke lapangan di dapatkan tiga belas berita rakyat yang tersebar di seluruh wilayah kabupaten pandeglang. cerita rakyat tersebut diantaranya Cerita Rakyat Pangeran Pandeglang dan Putri Cadarasi,, Legenda Tanjung Lesung, Cerita Rakyat Batu Tulis Citaman, Cerita Rakyat Syekh Maulana Mansyurudin Cikadueun. Cerita Rakyat Prasasti Batu Tulis Munjul, Cerita Rakyat Sungai Cisajir, Cerita rakyat Asal Mula Desa Mekarjaya Kec Cikedal, Cerita Rakyat Regen Boncel Caringin, Cerita Rakyat Situ Cikedal, Cerita Rakyat Ki Mintul dan Nyi Mintul, Cerita Rakyat Ki Ipuh Raja Buhaya Ti Ciliman, Cerita Rakyat Nyi Jompong, Cerita Rakyat Leuwi Lamot dan Belut Raksasa dan Cerita Rakyat Sumur Cidewata.

Cerita rakyat kabupaten Pandeglang dapat di bedakan menjadi beberapa kelompok. Mengacu pendapat Brunvand (dalam Danandjaja, 2005: 67) membagi legenda ke dalam empat kelompok yaitu : (a) legenda keagamaan (religius legend), (b) legenda alam gaib (supernatural legend), (c) legenda

perseorangan (personal legend), (d) legenda setempat (local legend ). Maka pembagian kelompok cerita rakyat pandeglang sebagai berikut.

\section{Legenda Keagamaan}

Legenda keagamaan adalah cerita yang mengisahkan orang orang suci, orang orang saleh dalam penyebaran agama yang dilakukanna. Pada cerita rakyat pandeglang yang terkategorikan cerita rakyat keagamaan adalah cerita rakyat Syekh Maulana Manshurudin Cikadueun. Cerita rakyat ini mengisahkan perjalanan ulama besar Banten dalam menyebarkan agama islam di wilayah Banten bagian selatan yaitu Kabupaten Pandeglang. dilihat dari kesejarahannya kisah Syekh Maulana Manshurudin Cikadueun terjadi pada zaman kesultanan Banten.

2. Legenda perseorangan (personal legend)

Cerita rakyat yang tergolong legenda perseorangan adalah legenda yang menceritakan tokoh tokoh tertentu. cerita Rakyat Regent Boncel adalah Cerita rakyat yang tergolong kepada cerita rakyat perseorangan. Cerita rakyat ini mengisahkan seorang regent yang tidak mengakui orang tua nya karena orang tuanya miskin. Pada akhirnya ia menyesali semua yang telah dilakukan kepada orang tuanya. Dilihat dari unsur kesejarahan kisah ini terjadi pada zaman penjajahan belanda.

3. Legenda setempat (local legend)

Cerita rakyat yang termasuk kedalam legenda setempat adalah cerita yang berhubungan dengan asal usul suatu tempat, nama tempat dan bentuk topografi, yaitu bentuk permukaan suatu daerah yang berbukit bukit, berjurang dan sebagainya. Cerita rakyat kabupaten Pandeglang yang tergolong kedalam legenda setempat 
diantaranya Cerita Rakyat Pangeran Pandeglang dan Putri Cadarasi, Legenda Tanjung Lesung, Cerita Rakyat Batu Tulis Citaman, Cerita Rakyat Prasasti Batu Tulis Munjul, Cerita Rakyat Sungai Cisajir, Cerita rakyat Asal Mula Desa Mekarjaya Kec Cikedal, Cerita Rakyat Situ Cikedal, Cerita Rakyat Nyi Jompong, Cerita Rakyat Sumur Cidewata dan Cerita Rakyat Leuwi Lamot dan Belut Raksasa.

\section{Cerita rakyat Pangeran Pandeglang} dan Putri Cadasari merupakan cerita rakyat yang menjadi asal mula penamaam kabupaten Pandeglang. Cerita rakyat ini mengishkan seorang putri yang dipaksa menikah oleh seorang jawara yang berwatak jahat. Sang putri pun bingung dan bertemulah dengan seorang kakek tua dan menceritakan seluruh keluh kesahnya. Akhirnya kekek tersebut menyarankan kepada putri untuk memberikan syarat kepada pangeran cunihin tersebut. Kakek tua itu sebenarnya adalah pangenan pende kekasih putri cadasari yang di kutuk oleh pangenan cunihin menjadi kakekkakek tua. Untuk menolaknya maka ia mengajukan persyaratan agar ia meliubangi sebuah batu dalam satu malam dan harus masuk kedalam batu tersebut. Akhirnya kekuatan jawara berwatak jahat itu berkurang dan akhirnya dia menjadi tua. Disitulah pangeran pandeglang menjadi muda kembali.

Cerita Rakyat Legenda Tanjung Lesung mengisahkan soerang putri yang berkuasa di kerajaan hujung kuntilanak. Ia menikah dengan seorang pemuda gagah berani. Tetapi di akhir cerita kerajaan ini hilang karena terjadi bencana yang maha dahsyat. $\begin{array}{lllr}\text { Cerita rakyat Batu Tulis } & \text { Munjul } \\ \text { merupakan cerita rakyat yang } & \text { rakan } \\ \text { diperkirakan terjadi pada zaman }\end{array}$ kerajaan Tarumanegara. Mengisahkan perjalanan Purnawarman raja kerajaan tarumanegara dalam menaklukan daerah dan perluasan wilayah kekuasaannya.

Cerita rakyat batu tulis citaman mengisahkan perjalanan sekelompok mubalig dalam menyebarkan agama islam di wilayah Banten. Kisah tersebut di perkirakan terjadi pada zaman kerajaan Pajajaran dan peralihan ke zaman kerajaan islam banten.

Cerita rakyat sungai Cisajir mengisahkan seorang jawara yang membuat sungai seorang diri untuk megairi sawah. Tetapi setelah berhasil membuat sungai warga tersebut berkhianat dan tidak menepati janji yang telah disepakati sebelumnya yaitu memberikannya seekor kerbau bule. Akhirnya ki sajir meninggal dan sungai tersebut dirusak oleh kerbau bule siluman.

Cerita Rakyat Asal Usul Desa Mekarjaya mengisahkan dua tokoh jawara yang bertarung kesaktian yaitu ki manjaya dan ki mundesa. Ditengah pertarungan ki manjaya menghantikan pertarungan tersebut dan mengjak ki mundesa berdamai. Tetapi itu hanyalah siasat licik, karena setelah itu ki manjaya mengajak bepresta denga minum air bersama sebagai tanda persahabatan. Tetapi kimanjaya telah memesukan keris kedalam bungbung air minum yang akan di berikan ke ki mundesa. Seketika kimundesa tewas.

Cerita Rakyat Situ Cikedal menceritakan seorang pangeran yang nyasar ke alam manusia dan ditemukan oleh seorang gadis cantik. Saat tersesat pangeran tersebut hilang ingatan, karena pangeran tersebut tampan 
akhirnya gadis itupun jatuh cinta dan mereka menikah. Tetapi saat gadis tersebut mengandung anaknya, tibatiba pangeran tersebut ingatannya pulih dan ingat siapa dirinya. Akhirnya pangeran tersebut meniggalkan isterinya. Bebrapa lama kemudian pangeran tersebut datang kembali dan meminta maaf kepada isterinya. Tetapi isterinya tidak terima karena telah ditinggalkan. Akhirnya untuk membuktikan rasa cintanya pangeran tersebut bersumpah bahwa rasa cintanya akan membanjri daerah tersebut dan jadilah situ cikedal.

Cerita rakyat curug Nyi Jompong menceritakan seorang gadis bernama nyi Jompong yang akan di perkosa oleh tentara Belanda. Untuk menjaga kehormatannya nyi jompong berlari ke hutan dan menjatuhkan diri di sebuah ait terjun yang sangat curam. Curug tempat nyi jompong menjatuhkan diri sekarang bernama curug nyi jompong. Konon katanya di curug tersebut ada sebuah batu yang merupakan penjelmaan nyi jompong. Disetiap bulan nya batu tersebut mengeluarkan air berwarna merah yang mengindikasikan bahwa nyi jompong tersebut menstruasi. Tetapi saat ini batu tersebut tidak mengeluarkan air berwarna merah lagi dengan indikasi bahwa nyi jompong sekarang sudah meunupus.

Cerita rakyat sumur cidewata mengisahkan seorang pemuda yang gemarnya hanya berburu burung ke hutan. Suatu ketika sedang berburu di sebuah air terjun ada bidadari yang sedang mandi. Dengan seketika pemuda tersebut mengambil selendang salah satu diantara mereka. Akhirnya satu orang putri tak bisa kembali ke kayangan. Pemuda tersebut menghampiri putri itu dan akhirnya mereka menikah. Setelah sekian lama selendagn yang di sembunyiakn pemuda tersebut ditemukan dan dia kembali ke kayangan. Lalu pemuda tersebut menyusul isterinya ke kayangan. Sampai sama semua putri sama persis tak ada yang beda. Raja kayangan menyatakan bahwa ketika pemuda tersebut dapat menentukan yang mana isterinya maka ia boleh membawa isteinya pulng ke bumi. Dengan bantuan lalat pemuda tersebut dapat mengetahui yang mana isterinya dan ia bawa kembali ke bumi dan hidup berbahaga.

Cerita rakyat leuwi lamot dan belut raksasa merupakan cerita rakyat yang menceritakan dua orang suami isteri yang menginginkan seorang anak. Lama menunggu akhirnya mempunyai anak. Saking bahagia dan sayang terhadap anaknya kemanapun mereka pergi anak itu selalu di bawa termasuk ketika bekerja di lading. Suatu ketika sedang bekerja di lading anak mereka simpan di ayunan. Tak berapa lama anak mereka hilang dan ketika dilihat tidak ada bekas darah hanya ada bekas air saja. Selanjutnya orang tua anak tersebut mengikuti jejak air tersebut pas di ikuti ternyata bekas air itu menuju ke sebuah leuwi yang begitu dalam yang diisi sekor belut raksasa. Akhirnya disimpulkan bahwa anaknya di telan atau dalam bahasa sunda di lamot oleh belut raksasa tersebut.

\section{b. Pemanfaatan Cerita Rakyat Pandeglang Sebagai Bahan Pembelajaran Apresiasi Sastra}

Bahan ajar adalah segala bentuk bahan yang digunakan untuk membantu guru dalam melaksanakan proses kegiatan pembelajaran. Bahan pembelajaran dapat berupa bahan tertulis maupun bahan 
tidak tertulis. Fungsi bahan pembelajaran adalah membantu guru dalam kegiatan belajar mengajar dan membantu siswa dalam proses belajar. Pemilihan bahan pembelajaran sastra dapat dilakukan dengan memperhatikan karakteristik sastra anak disesuaikan dengan kurikulum yang berlaku. Selain itu juga pemilihan bahan ajar di harapkan memanfaatkan kebudayaan daerah yaitu cerita rakyat. Pemanfaatan cerita rakyat dalam pembelajaran sastra juga sebagai upaya pelestarian cerita rakyat tersebut. Ada beberapa langkah yang dilakukan dalam memanfaatkan cerita rakyat sebagai bahan pembelajaran yaitu sebagai berikut.

\section{Perencanaan Pembelajaran}

$\begin{array}{lll}\text { Pemanfaatan } & \text { cerita } & \text { rakyat } \\ \text { Pandeglang } & \text { sebagai } & \text { bahan } \\ \text { pembelajaran } & \text { apresiasi } & \text { sastra }\end{array}$
dilakukan melalui langkah-langkah sebagai berikut. Pertama Analisis $\mathrm{KI} / \mathrm{KD}$, analisis $\mathrm{Ki} / \mathrm{KD}$ dilakukan untuk menentukan kompetensi yang ingin dicapai dengan penggunaan cerita rakyat pandeglan sebagai bahan pembelajaran. Kedua analisis silabus, analisis silabus dilakukan untuk menentukan pada KI/KD mana bahan pembelajaran yang berupa cerita rakyat dapat di terapkan. Ketiga menyusun RPP, menyusn RPP dilakukan untuk menentukan langkah-langkah yang akan dilakukan dalam proses pembelajaran tersebut. Beberapa kegiatan yang dilakukan dalam penyusunan RPP seperti menentukan IPK, menentukan tujuan, menentukan materi atau bahan ajar, menentukan metode, menyiapkan media, langkah kegiatan pembelajaran, penilaian dan tindak lanjut.

\section{Perencanaan Penilaian}

Perencanaan penilaian dilakukan untuk mengukur pencapaian hasil belajar peserta didik. Dalam penelitian ini, penilaian hasil belajar dilakukan terhadap aspek sikap, pengetahuan, dan keterampilan.

3. Pelaksanaan Pembelajaran dan Hasil Penilaian

Tahap pelaksanaan pembelajaran adalah tahapan penggunaan cerita rakyat pandeglang sebagai bahan pembelajaran apresiasi sastra dengan mengikuti langkah-langkah pada RPP yang telah dibuat sebelumnya. Dilanjutkan dengan pemahaman siswa terhada isi cerita rakyat tersebut.

\section{Tanggapan Siswa dan Guru}

Selain angket, untuk mengetahui tanggapan atau respon terhadap penggunaan bahan ajar cerita rakyat lokal atau setempat dalam pembelajaran apresiasi sastra, Penulis melakukan wawancara terhadap sejumlah siswa dan guru. Dari hasil wawancara didapatkan data bahwa masih banyak siswa dan guru yang tidak tahu mengenai cerita rakyat yang ada di daerahnya sendiri. Karena selama ini pembelajaran apresisasi sastra sering menggunakan bahan pembelajarn berupa derita yang sudah popular di masyarakat seperti malin kundang dan legenda tangkuban perahu. Siswa dan guru yang di wawancarapun menyatakan senang dan menilai pembelajaran apresiasi sastra dengan bahan ajar cerita rakyat dari daerah mereka sendiri lebih menarik, dan membuat mereka bertambah pengetahuan tentang sejarah daerah mereka sendiri serta tertantang untuk ikut 
serta melestarikannya dengan cara menceritakan kembali di lingkungannya masing-masing

\section{KESIMPULAN}

Terdapat empatbelas cerita rakyat yang berada di seluruh wilayah kabupaten Pandeglang. cerita rakyat tersebut diantaranya Cerita Rakyat Pangeran Pandeglang dan Putri Cadarasi, Legenda Tanjung Lesung, Cerita Rakyat Batu Tulis Citaman, Cerita Rakyat Syekh Maulana Mansyurudin Cikadueun. Cerita Rakyat Prasasti Batu Tulis Munjul, Cerita Rakyat Sungai Cisajir, Cerita rakyat Asal Mula Desa Mekarjaya Kec Cikedal, Cerita Rakyat Regen Boncel Caringin, Cerita Rakyat Situ Cikedal, Cerita Rakyat Ki Mintul dan Nyi Mintul, Cerita Rakyat Ki Ipuh Raja Buhaya Ti Ciliman, Cerita Rakyat Nyi Jompong, Cerita Rakyat Leuwi Lamot dan Belut Raksasa dan Cerita Rakyat Sumur Cidewata.

Berdasarkan hasil analisis keempatbelas cerita rakyat tersebut terbagi kedalam tiga golongan cerita rakyat yaitu cerita rakyat keagamaan, cerita rakyat perseorangan dan cerita rakyat wilayah setempat. Ditinjau dari unsur kesejarahan cerita rakyat tersebut terjadi mulai dari zaman kerajaan Salakanagara, Tarumanegara, Pajajaran, kerajaan islam Banten sampai pada zaman penjajahan Portugis, Belanda, Jepang dan sampai ke Zaman Kemerdekaan Indonesia. keepatbelas cerita rakyat Pandeglang dapat diguakan sebagai bahan pembelajaran apresiasi sastra di berbagai jenjang pendidikan seperti SMP, SMA, bahkan perguruan tinggi. Bahkan dapat pula di gunakan di tinggakatn PAUD dan SD dalam pemblajaran bercerita untuk judul-judul cerita rakyat tertentu. seperti Cerita Rakyat Ki Ipuh Raja Buhaya Ti Ciliman dan cerita rakyat Leuwi Lamot dan Belut Raksasa. Untuk pemanfaatan sebagai bahan pembelajaran apresiasi sastra terdapat beberapa langkah yang ahrus di tempuh diantaranya perencanaan pembelajaran, perencanaan penilaian, pelaksanaan pembelajaran dan hasil penilaian, dan tanggapan siswa dan guru untuk mengetahui respon penggunaan cerita rakyat setempat sebagai bahan pembelajaran apresiasi sastra.

\section{Referensi}

[1] Danandjaja, James. 2007. Folklor Indonesiai Ilmu Gosip Dongeng dan Lainlain. Jakarta: Grafiti.

[2] Effendi. S. 2006. Bimbingan Apresiasi Puisi. Jakarta: Pustaka Jaya.

[3] Irman, dkk. 2008. Bahasa Indonesia Untuk SMK/MAK Semua Program Keahlian Kelas XII. Jakarta: Dinas Pendidikan Nasional.

[4] Iskandar Wassid dan Dadang Suhendar. 2011. Strategi Pembelajaran Bahasa. Bandung: PT Remaja Rosda Karya.

[5] Lestari, Ika. 2013. Pengembangan Bahan Ajar Berbasis Kompetensi. Padang: Akademia Permata.

[6] Pontoh, Nia K. 2009. Pengantar Perencanaan Perkotaan. Bandung : ITB

[7] Ruhimat, T. dkk. 2009. Kurikulum dan Pembelajaran. Bandung: Jurusan Kurtekpen FIP UPI

[8] Sudjiman, Panuti. 2006. Kamus Istilah Sastra. Jakarta: Universitas Indonesia.

[9] Sugiyono. 2012. Metode Penelitian Kombinasi (Mixed Methods). Bandung: Alfabeta. 